\title{
HOW FAMILIARITY IMPACTS INFLUENCE IN COLLABORATIVE TEAMS?
}

\author{
Singh, Harshika (1); \\ Becattini, Niccolo (1); \\ Cascini, Gaetano (1); \\ Škec, Stanko (2) \\ 1: Politecnico di Milano; \\ 2: University of Zagreb
}

\begin{abstract}
Individual traits strongly impact team composition and the biases arising from them can also impact design activities. One such bias highlighted in the study is the familiarity bias (i.e., a bias that might be present between the two individuals due to their prior acquaintance). In order to detect the familiarity bias, participants from 4 universities who evaluated their peers and rated them for (1) their perceived degree of influence, (2) trust, (3) the amount of agreement they had with the other team member and (4) the amount of agreement the other individual in the team had with them. It was found that familiarity bias exists in collaborative teams. Its impact on the four variables, especially on influence, was discovered. In the end, the study briefly highlighted the importance of studying the factors (like the one revealed in this study) that affect influence in design teams as it eventually impacts design outcome. It was found that the individuals who explore most idea clusters, are less likely to be perceived influential and teams having the most influence produced a smaller number of idea clusters. Overall, the study contributes to understanding the factors affecting human cognition and behaviour in the design teams.
\end{abstract}

Keywords: Collaborative design, Design cognition, Teamwork, Design education

\section{Contact:}

Singh, Harshika

Politecnico di Milano

Department of Mechanical Engineering

Italy

harshika.singh@polimi.it 


\section{INTRODUCTION}

Though co-design teams are increasingly becoming popular, there are several factors that may impact its performance (Kleinsmann and Valkenburg, 2008). In order to understand and address these factors, more emphasis is being given to study the collaborative design process as a 'social process where social interactions, roles and relationships cannot be ignored in the analysis of design activity teamwork' (Cross and Cross, 1995). The teams are often composed of individuals who have no prior acquaintance, are from different locations or have different expertise. Several biases may exist in collaborative teams that may arise from different sources, for example, the individual cognitive state, the social context or the organisation structure. As the teams consist of different individuals, and the acquaintance with each other is not the same, bias may arise due to the familiarity between the members that may impact individuals' perception of their peers. It is known that individuals' intrapersonal factors like an individual's familiarity with the other team members may affect team social psychology and could influence team effectiveness (Stokols et al., 2008). Thus it is important to study its impact on co-design teams. Familiarity here is referred to as the state of acquaintance between the two individuals. Thus, the bias arising due to the familiar state between the two individuals in a team is referred to as familiarity bias.

The interaction between the team members gives rise to social influence (Myers, 1982) that is not evenly distributed in teams. Some individuals might be perceived as more influential than others and this perceived degree of influence impacts individual thinking thus, the design outcome (Singh et al., 2020a). As working in teams is gaining momentum in many fields, understanding how the design output is impacted with respect to the amount of influence perceived by its members in a design team, could aid in explaining team performance. Considering the impact of an individual's interpersonal attribute like familiarity on the team's social variables like perceived influence could further help in improving team coordination. Therefore, the purpose of the paper is to study how an individual's familiarity with the other team members affects the team's social variables of the collaboration which in turn impacts team outcomes.

The study could be beneficial to other researchers using peer evaluation in co-design teams as it is informative on the presence of familiarity bias when analysing data. Exploring the role of familiarity in team collaboration is crucial as it affects product development (Ramachandran et al., 2017), hence the insights could be used in suitable team management strategies. By controlling the desired amount of familiarity in teams, the full-creative potential could be harnessed (Singh et al., 2009).

Considering the motivation behind the work, the paper starts with a brief description of the past literature with the synthesis of gaps. This is followed by a description of the experiment and the method implemented for data collection and analysis. The last part of the paper consists of the results obtained along with the discussion and the conclusion of the work.

\subsection{Background}

\subsubsection{Biases in teams}

The study of biases in teams can be carried out with different techniques like through observations, selfassessment, and so on. Among these "peer evaluation is becoming popular as they are an important tool to gain knowledge about individuals' beliefs about their peers. However, an individual's perception of the other as he/she indicates in the peer evaluation could be affected by many biases (Sherrard et al., 1994) and factors like team member characteristics (Watson et al., 2010) or social styles (May and Gueldenzoph, 2006). Studies were found where peer rating bias was based on gender (Falchikov et al., 1997; Aryadoust, 2016), while others discovered that the student peer ratings were not affected by gender but significantly by race (Dingel and Wei, 2014; Layton and Ohland, 2000; Hinds et al., 2000). It is known that 'similar-to-me effect' exists (Latham and Wexley, 1982), where individuals who are similar (e.g. personality, attitudes or background) are rated higher while others showed that friendship was the dominant form of bias in collaborative team peer perceptions (Thompson, 2001).

From the above works, it is clear that biases exist in teams. However, it is also seen that when two individuals are familiar with each other, it affects social forging (i.e., social coordination, collaboration and collective decision) (Oesch and Dunbar, 2018). It could be because an individual is comfortable with the familiar individual that impacts interpersonal relationships. 


\subsubsection{Familiarity bias in the social variables}

If co-design is considered as a social process (Cross and Cross, 1995), the factors affecting the interactions, roles and relationships among the team members should be considered. It is known that the degree of influence perceived by team members from each other determines team performance (Singh et al., 2020b); trust in teams is responsible for work effectiveness (Costa, 2003) and factors affecting idea selection (like agreement in solutions) are crucial to study (Lindley et al., 2017). Moreover, the prior acquaintance between individuals (i.e. familiarity with each other) affects social attributes (Singh et al., 2009) and influences team psychology (Stokols et al., 2008). The prior acquaintance might lead to the formation of strong ties among individuals that impact social influence in teams. This may lead to conformity during decision making or affects agreement in team processes (Perry-Smith and Shalley, 2003; Jones and Roelofsma, 2000; Ferguson et al., 2020). Additionally, trust, that may arise from how well the two individuals have known each other previously (Granovetter, 1973).

Little is known about the impact of familiarity bias on the above factors as they cover key social aspects of the design process in collaborative teamwork (Woodman et. al, 1993; Stokols et al., 2008) which can shed a light on team behaviour and provide additional explanations on expected outcomes. Hence, the work studies the impact of familiarity on the four social variables: the individual's perceived degree of influence, the amount of trust it has on the other team member, the amount of agreement it had with the other team member and the amount of agreement the other individual in the team had with him/her.

\subsubsection{Research gaps, objective and contribution}

The studies found in the literature that have studied familiarity, have used self-report questionnaires to quantify individuals' familiarity with other team members (Oesch and Dunbar, 2018; Adams et al., 2005; Wetmore et al., 2010). A criticism of these kinds of study is that each individual rates its perceived familiarity with the other team member and the understanding of familiarity is different for every individual. Extensive research in the area of analysing and revealing the biases and factors influencing peer evaluations has been done. However, no research could be found that have used peer-evaluations as a tool to reveal the presence of familiarity bias on social variables of co-design that are considered in the paper. In order to address the above gaps, the following research question was identified:

How does familiarity impacts the social variables of collaborative teams?

The main contribution of the work lies in an attempt to reveal the presence of familiarity bias without using the self-reported data and its impact on the peer-evaluated social variables in co-design teams. Additionally, it has been investigated that influence impacts individual thinking during brainstorming (Brown and Paulus, 1996) and decision-making (Keum and See, 2017), however, its effect on design outcome (in terms of quality and exploration) still needs more investigation. Thus, the paper also briefly shows the importance of studying social variables in teams like influence as it impacts design outcomes in terms of exploration.

\section{METHOD}

\subsection{Experiment details}

It is already known that strong ties exist between the people who share similarities (in this case same university or geographical location) and is associated with relatively higher 'frequent interactions, high emotional closeness, and reciprocity' (Perry-Smith and Shalley, 2003). Thus, to study familiarity, data was collected from a co-design workshop with 40 MS students in Mechanical Engineering from universities located in 4 different European countries (Italy, Croatia, Slovenia and Austria).

Familiarity here refers to the state where two individuals belong to the same institution and have been introduced to each other prior to working collaboratively with other individuals (from different institutions) on a design project ${ }^{1}$. The individuals from different institutions that have not met or known each other before the design project, hence, are referred to as non-familiar.

1 Though all the 4 universities are from different countries in Europe, the bias emerging from one's nationality was not considered because in many cases the individuals had nationality different from the country where they were studying. 
The student population ranged from 23-27 years with 38 males and 2 females. The workshop was carried out in a live setting, at Politecnico di Milano, within the second year of activities of the ELPID project (Becattini et al., 2020), whose overall aim is to develop an E-learning Platform for Innovative Product Development.

Five teams of 8 team members were composed where 2 students from the same universities were kept in one team. The workshop took place at the beginning of the semester to allow the different team members to know each other and get accustomed to the design methods and tools as well as ICT technology that they were supposed to use throughout the semester. To apply these tools proficiently, the five teams worked on the same design task for 3 days. The design task required students to ideate and develop a concept for an entertainment system in the university campus of Politecnico di Milano at Lecco that could help students to relax and integrate them with the local population. The conceptual solutions had to be compatible with a budget, the current structure of the campus, and self-sustainable.

\subsection{Data collection}

The collection of peer evaluation data with students' opinion on social variables was done during the second day of the workshop when team dynamics was more consolidated and less susceptible to the first impressions. The paper questionnaire was kept optional and short. The peer evaluation questionnaire format was inspired by Ohland et al., (2012). Each team member (for example, $R l$ in Table 1) rated the other members of its team with a score on a 5 point Likert scale ( $1=$ low, $5=$ high) to indicate how much they are influential in the team $[I]$, how much they trust them $[T]$ and their degree of the agreement they had with their respective peers $[A S O]$ and the degree of the agreement the respondents believed their peers had with them during the design activity $[A O S]$ (shown in columns 4-7 in Table 1).

Table 1 An excerpt of collected data about social variables

$\begin{array}{llllllllll}\text { Team } & \text { Respondent } & \begin{array}{l}\text { Team } \\ \text { member }\end{array} & \text { I } & \text { T } & \text { A_SO } & \text { A_OS } & \begin{array}{l}\text { Value } \\ \text { sum }\end{array} & \begin{array}{l}\text { Same } \\ \text { university }\end{array} & \text { Delta } \\ & \begin{array}{l}\text { Respondent } \\ \text { R1 }\end{array} & \text { TM 1 } & 5 & 4 & 5 & 5 & 19 & \text { True } & \\ & & & & & & & & & \\ & \text { TM 2 } & 4 & 4 & 5 & 5 & 18 & \text { False } & 1 \\ & \text { TM 3 } & 5 & 3 & 3 & 3 & 14 & \text { False } & 5 \\ \text { TM n } & 3 & 3 & 2 & 3 & 11 & \text { False } & 8\end{array}$

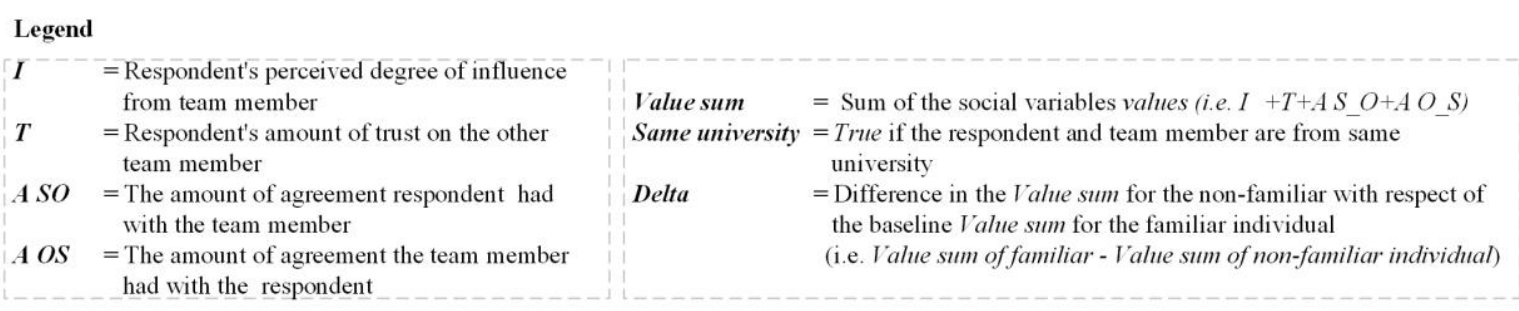

To maintain the anonymity of the respondents, each participant was associated with a unique colour code (i.e., the colour of the post-it). An example can be seen from Figure 1(left) where the team members had different colour post-its (in this case pink, yellow, blue, green, pastel pink and so on).

When filling the questionnaire, respondents referred to their peers by the colour codes. Links between the post-it colours and institution remained explicit in order to explore the familiarity aspect during the analysis of data (Table 1, column 9). The post-it-based data collection provided elements concerning the design outcome and the design process in the team. Moreover, this enabled the estimation of the degree of exploration of the design space by the team (number of post-its on a given sheet) and by individuals (number of post-its of the same colour and their degree of distribution in the different clusters of ideas on a given sheet) as seen from an example in Figure 1(right). 

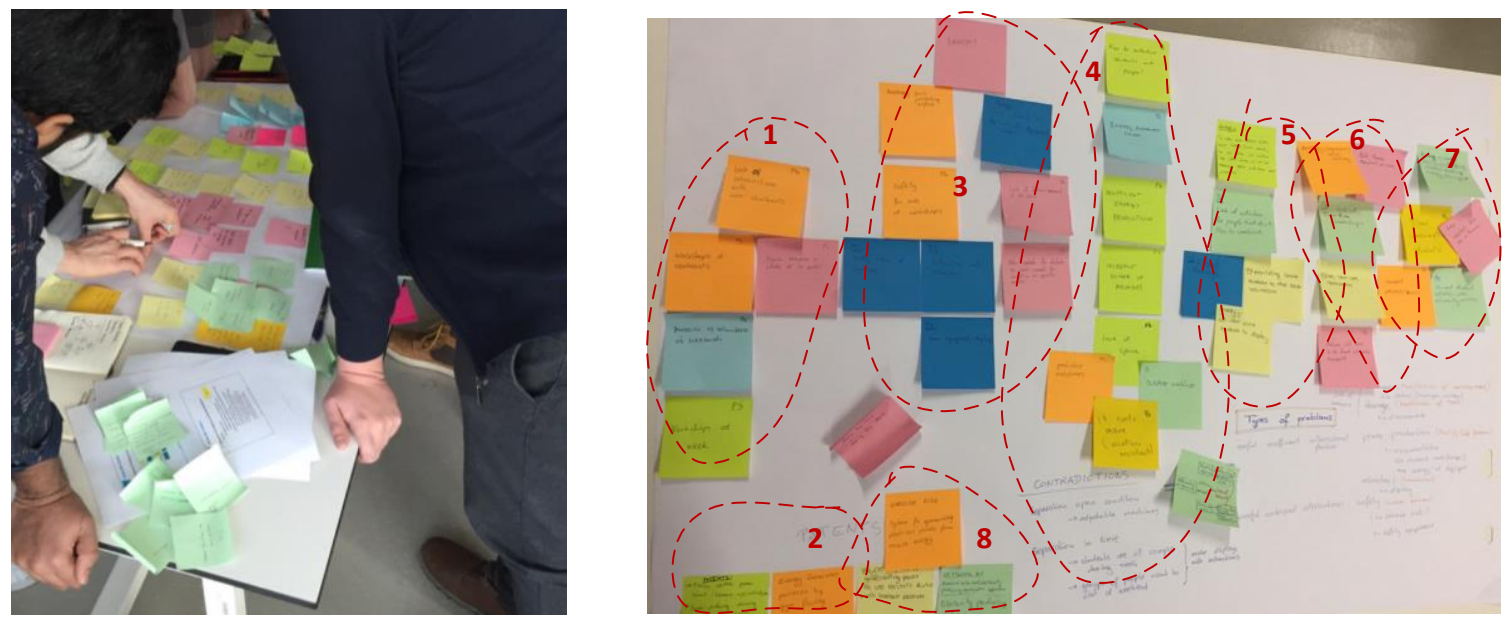

Figure 1(left) one of the teams during the idea generation session; (right) an example of ideas produced by one of the teams that were clustered. The red dotted line represents a cluster of ideas and post-it colours representing the team members.

\subsection{Data processing}

The experimental data allowed checking on how familiarity affects social variables in collaborative design teams and its concomitant effect on design outcomes. More specifically, the relationship between familiarity bias and social variables was analysed after some data processing.

To see whether the familiarity bias is present or not in the dataset, the sum of scores (Value sum - Table 1 , column 8) was used. This score for familiar teammates (same university) served as the baseline for the emergence of differences with non-familiar teammates (other universities). The difference between these scores (Delta - Table 1, column 10) is positive if the familiar teammate was rated better than the nonfamiliar one and vice versa.

To see if there is any impact of investigated topics on the design outcome, the data collected by means of the post-its was further processed in the form of the cluster of ideas (Figure 1 right). These clusters were generated based on the workshop tutorial where the teams had to break down the design task into subproblems and generate solutions to these sub-problems, hence the ideas addressing one aspect of a problem were counted as one cluster (as highlighted in a red enclosure in Figure 1 right). The number of clusters of ideas is equivalent to the spread of the solution in the design space (Dove et al., 2018). As each participant used unique colour post-its for his/her ideas, the number of different colours in all clusters of ideas generated by a team is an estimator of individuals' exploration of the design space.

\section{RESULTS AND DISCUSSION}

\subsection{Detection of the familiarity bias}

To answer the research question, the presence of the familiarity bias was investigated in the dataset. This was assessed by counting the number of times a respondent rated a familiar individual with a score higher than the one assigned to a non-familiar one. Counting the number of positive and negative values for "Delta" estimated the magnitude of the bias in the dataset. Figure 2 (left) shows the number of times a familiar individual was rated higher than a non-familiar one.

This indicates that there might be a presence of familiarity bias in teams as the familiar individuals were giving higher scores to each other. A significant difference in the sum of the scores given by a respondent (Value sum) to its familiar and non-familiar team members was found (Mann-Whitney $\mathrm{U}=18290.0$, p-value $<0.001$ ). This could be seen from the boxplot shown in Figure 2 (right), where non-familiars were rated lesser $(\mathrm{M}=16.04, \mathrm{SD}=2.75)$ than the familiar individuals $(\mathrm{M}=17.3$, $\mathrm{SD}=2.2$ ) by a respondent. On further investigation, a positive Point-Biserial correlation ${ }^{2}$ between

2 Point-biserial correlation coefficient was used because one of the variables (in this case Same university in Table 1 was either true or false) was dichotomous. Same number of data points for familiar and non-familiar were used. 
familiar and non-familiar with respect to the sum of the values entered by the respondent showed that a non-familiar is more likely to be scored lower than the familiar individual from the same university $(\rho=0.4$, p-value $=0.002)$.
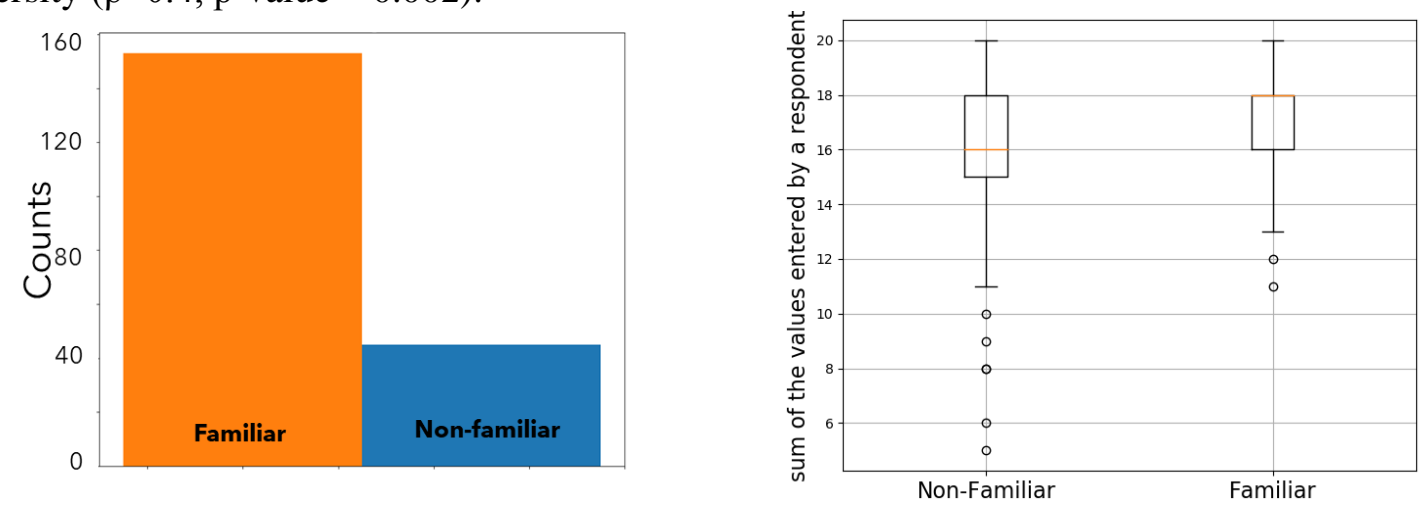

Figure 2 (left) Number of times when a familiar individual was rated higher than the nonfamiliar ones; (right) Boxplot where non-familiar individuals are more likely to get lower scores than familiar

\subsection{Analysis of the familiarity bias}

As the familiarity bias emerged in the data set, further analysis was conducted to find out the relationship between the sum of the values entered by a respondent for social variables of co-design (Value sum) and the difference in the sum of values with respect to the familiar individual scores (Delta). This enabled measuring the order of magnitude of the difference in the evaluation, beyond the mean values presented in Figure 2 (right). Figure 3 refers to the subset of data concerning the evaluation of non-familiar teammates. It shows a negative correlation between the overall score assigned to non-familiar teammates and the one assigned to familiar ones (Kendall correlation $\rho=-0.51$, p-value $<0.00$ ). This was further supported by performing a Chi-square test by dividing the plot in Figure 3 into four quadrants and counting the data points that lie in each of them. The Chisquare test result shows a strong association between the sum of the values entered by the respondent and the difference between the scores he/she gave to the familiar and non-familiar individual $(\chi 2=$ $38.58, \mathrm{p}<0.001)$.

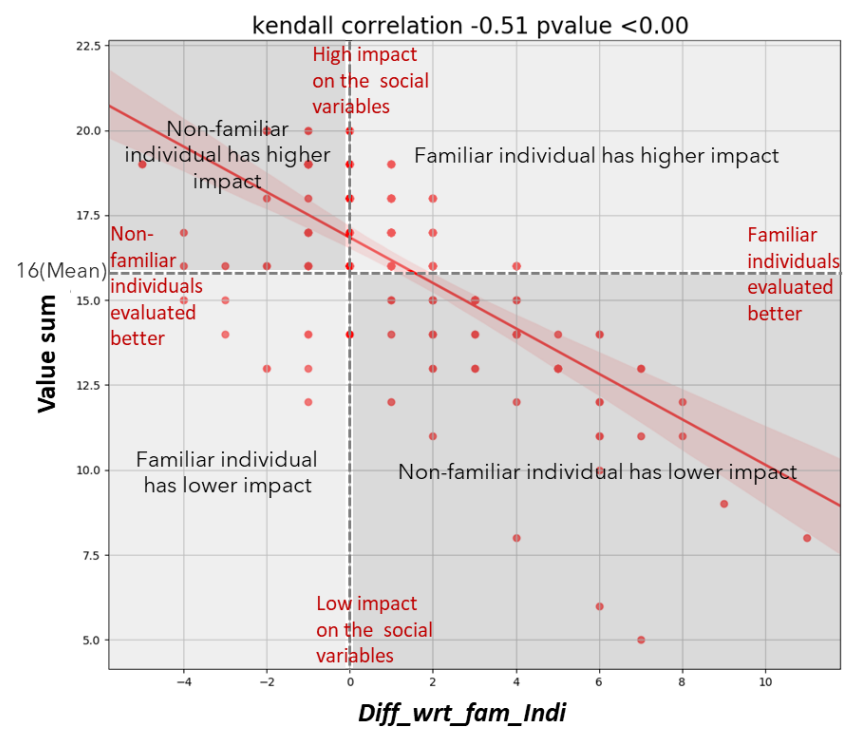

Figure 3 Correlation plot showing the negative relationship between the overall evaluation of non-familiar individuals with reference to the familiar one.

\subsection{Presence and effect of the familiarity of the social variables of the co-design}

In order to see the impact of familiarity bias on the individual social variables considered in the study, the steps are shown in Figure 4 were followed to plot Figure 5 (left). 


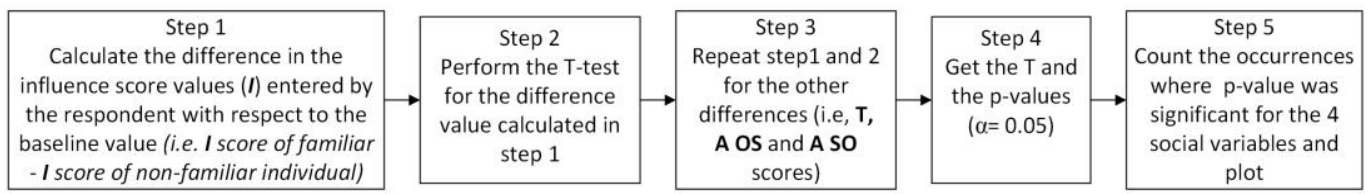

Figure 4 Analysis for showing the presence of familiarity bias on social variables

Figure 5 (left) shows the counts of the significant differences in the values entered by a respondent for familiar and non-familiar individuals for the four social variables. In other words, Figure 5 (left) shows the impact of familiarity on the four social variables considered for team collaboration. Variables like the individual's agreement during the design activities were impacted by the presence of familiar individuals in teams. On the other hand, familiarity did not have a significant effect on trust. This could mean that co-designers may generate trust in their peers even if they are not familiar with them since the very beginning of the activity.
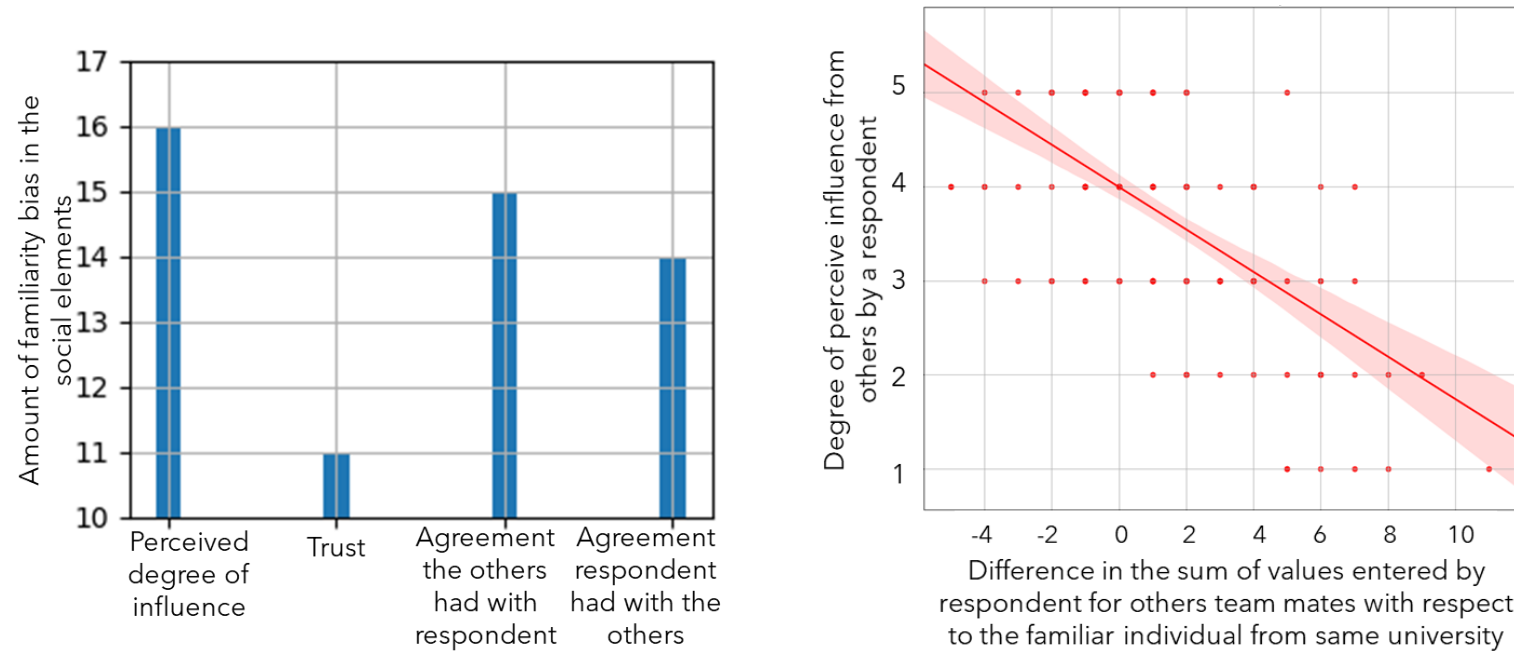

Figure 5(left) counts of the significant T-test values for different variables; (right) correlation plot showing the negative relationship

An important thing to be noted that in $40 \%$ of the cases (16/40), individuals' perceived degree of influence from their teammates was most impacted by familiarity bias. Further investigation showed a negative relationship in Figure 5(right) between an individual's perceived degree of influence $(I)$ and the difference in the sum of values with respect to the familiar individual scores (Delta) (Kendall correlation $\rho=-0.46$, p-value $<0.001$ ). The data points are shown in Figure 5(right) are overlapping as the peer evaluation questions were based on a 5-point scale.

\subsection{Significance of studying influence in design teams}
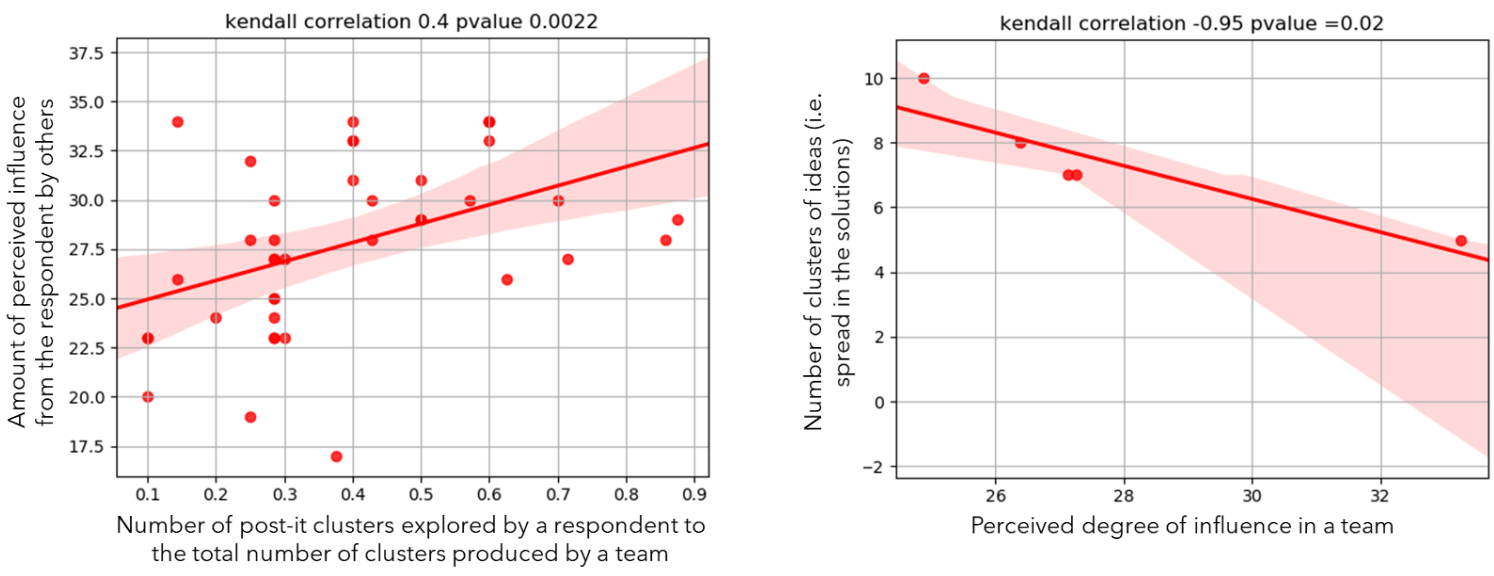

Figure 6 (left) positive correlation plot between perceived influence and the ratio of the clusters explored to the total number of clusters; (right) negative correlation plot between team influence and number of clusters 
The motivation for the study and analysis came from the observation that many co-design teams are subjected to familiarity bias that, in turn, impacts an individual's perceived degree of influence from its teammates as also demonstrated above (Figure 5). In order to study the relationship between the perceived influence and individual behaviour in design, the number of idea clusters explored as emerged from the collected post-its (Figure 1), provided another dataset for correlation analysis (Figure 6, left). It was found that the individuals who explore more clusters of solutions were not necessarily perceived influential, as there is a slightly positive correlation (Kendall correlation $\rho=0.4, p$-value $=0.002$ ). Then, it is also crucial to study the effect of perceived influence in design teams. The results for team-based analysis showed influence (affected by the familiarity bias) in turn affects design outcome. Figure 6 (right) collated the data from individual evaluations into team-based (Influence of the team= sum of individually perceived influence) and it was found that the teams who generated a higher number of post-it clusters, had less influence in them (Kendall correlation $\rho=-0.95$, $p$-value $=0.02$ ).

\subsection{Discussion}

Some objectives were identified to answer the research question of the study (i.e., how familiarity impacts social variables of collaborative teams?). The initial analysis revealed that familiarity bias exists in teams as the familiar individuals in most cases were rated higher than non-familiar. A positive relationship was observed between overall scores (i.e., the sum of scores of the 4 social variables) given to team member and the familiarity with him/her. On additional investigation, it was further confirmed that when a familiar individual is evaluated better, the impact of the non-familiar individual is less perceived. The results are in contrary to those who have found that gender and prior familiarity do not influence when individuals are evaluating each other (Paswan and Gollakota, 2004). One possible explanation could be that the study presented here dealt with the evaluation of the social variables and not with individual performance.

The study results also showed that the familiarity bias is present in the 4 social variables considered in the paper. Agreement during idea selection on the proposed solution demonstrated to be affected by the presence of familiar individuals. Thus, making clearer that familiarity bias might affect decisionmaking in teams (Ferguson et al., 2020). However, the familiarity between the two individuals had less impact on trust between them. It could be that trust is developed with time, or it depends on other factors that were unaccounted for in the study like domain knowledge or reputation.

One's perceived influence from its peer is positively correlated with familiarity. In other words, nonfamiliar individuals are less likely to be perceived as influential. A similar effect was seen when individuals who have more controlling characteristics, leader-like behaviour or demonstrate 'can-do attitude', are often evaluated higher by their peers (Watson et al., 2010; Dingel and Wei, 2014).

Lastly, it was seen from the results that it is important to further investigate the factors affecting influence in design teams as it in turns impacts design outcomes like exploration. The individuals who explore more design space are less likely to be considered influential. It is possible that influential individuals may have or show expert-like characteristics, despite novice, i.e. quickly commit to a single solution concept and do not search divergently (Cross, 2004). Although the study dealt with only 5 teams, it could be seen that a high amount of perceived influence in them results in the lesser spread of their solutions. Similar results were predicted by Singh et al. (2020a), where having high influence from well-defined influencers in teams resulted in the lesser spread of the solutions in the design space. Usually, it is seen that a team with a lower quality tends to search divergently in an attempt to improve that representation and a team with a high-quality has no need to refine their representation through broad search, hence lower exploration. Since nothing could be said about the quality of the solutions by the teams in this experiment, more investigation would aid in improving the understanding of the effect and role of influencers in design teams.

\section{CONCLUSION}

Good collaboration is the key characteristic of high-performing teams. As more and more organisations lean towards collaborative teams, there are many challenges including team members' prior acquaintances with each other that affect design activity. Familiarity bias was one such bias revealed from the study where diverse student teams worked on a collaborative design project. It was done by analysing the data that was collected through peer evaluation questionnaires where individuals were asked to rate their peers on different social variables. The social variables mainly one's perceived degree 
of influence from others was most impacted by the presence of familiarity bias. Besides, being rated lower than the familiar individual for measured the social variables, a non-familiar individual was also less likely to be perceived as influential. Lastly, the study shows the importance of studying factors (like the one revealed here) that impact the influence in the design team as it eventually affects design outcome. For example, it was seen that the individuals who explore most idea clusters, are less likely to be perceived influential and teams having the most influence produced the least number of idea clusters. Though the study provides clear evidence of the presence of familiarity bias in co-design teams, it is possible that the results might be affected by the presence of other factors that were unaccounted for in the study. The authors explored only the familiarity bias in co-design teams, the other biases like race, gender and so on were not investigated. The future experiments would aim for larger data sets to study other factors affecting one's perceived influence in teams and seeing its effect on solution quality. It was not possible to reveal how much the students from the same university (here assumed as familiar individuals), knew each other beforehand. In other words, it lacked provide a clear description of exactly how familiar these individuals were with their team members. Though the results are based on student project teams, their applicability to the professional teams need to be validated in future experiments.

Knowing the presence of familiarity bias on some of the social variables of co-design teams and its impact on the influence that ultimately affects design outcome, the study could be extended to gain useful information for team managers in obtaining balanced team composition for better results.

\section{ACKNOWLEDGEMENTS}

This study was done during the workshop of an Erasmus+ project (project reference number 2018-1HR01-KA203-047486) called E-learning Platform for Innovative Product Development (ELPID) whose objective of the platform is to develop an e-learning platform for product development. http://www.elpid.org/

\section{REFERENCES}

Adams, S., Roch, S. and Ayman, R. (2005). "Communication medium and member familiarity: the effects on decision time, accuracy, and satisfaction”, Small Group Research, Vol. 36 No. 3,pp 321-353. https://doi.org/10.1177/1046496405275232

Aryadoust,V. (2016), "Gender and academic major bias in peer assessment of oral presentations", Language Assessment Quarterly, Vol. 13 No. 1, pp 1-24. 10.1080/15434303.2015.1133626

Becattini, N., Škec, S., Pavković, N. and Cascini, G. (2020), "E-learning infrastructure prototype for geographically distributed project-based learning", Proceedings of the Design Society: DESIGN Conference, pp. 1667-1676. Cambridge University Press.

Brown, V. and Paulus, P. B. (1996), “A simple dynamic model of social factors in group brainstorming”, Small Group Research, Vol. 27 No. 1, pp. 91-114. https://doi.org/10.1177/1046496496271005

Costa, A. C.(2003),'Work team trust and effectiveness".Personnel Review, Vol. 32 No.5, pp. 605-622. https://doi.org/10.1108/00483480310488360.

Cross, N. and Cross, A. C. (1995), "Observations of teamwork and social processes in design", Design Studies, Vol. 16, pp. 145-170. https://doi.org/10.1016/0142-694X(94)00007-Z

Cross, N. (2004), "Expertise in design: an overview”, Design studies, Vol. 25 No. 5,pp. 427-441. https://doi.org/10.1016/j.destud.2004.06.002

Dingel,M. and Wei,W. (2014), "Influences on peer evaluation in a group project: an exploration of leadership, demographics and course performance", Assessment \& Evaluation in Higher Education, Vol. 39 No. 6, pp.729-742, 10.1 080/02602938.2013.867477

Dove, G., Abildgaard, S.J., Biskjær, M.M., Hansen, N.B., Christensen, B.T. and Halskov, K. (2018), “Grouping notes through nodes: The functions of post-it notes in design team cognition”, Design Studies, Vol. 57 , pp.112-134. https://doi.org/10.1016/j.destud.2018.03.008

Falchikov,N. and Magin,D. (1997) Detecting gender bias in peer marking of students' group process work, assessment \& evaluation in higher education, 22:4, 385-396,10.1080/0260293970220403

Ferguson, A., Stoverink, A. C. and Downes, P. (2020), "Exploring team familiarity as a buffer to external conformity pressure in decision-making teams", Academy of Management Proceedings, pp. 17079. Briarcliff Manor, NY 10510: Academy of Management.

Granovetter, M. S.(1973), "The strength of weak ties", American Journal of Sociology, Vol. 78 No.6, pp. 13601380.

Hinds, P. J., Carley, K. M., Krackhardt, D. and Wholey, D. (2000), “Choosing work group members: Balancing similarity, competence, and familiarity", Organizational behavior and human decision processes, Vol. 81 No. 2, pp. 226-251. 10.1006/obhd.1999.2875 
Jones, P. E. and Roelofsma, P. H. (2000), “The potential for social contextual and group biases in team decisionmaking: Biases, conditions and psychological mechanisms”, Ergonomics, Vol. 43 No. 8, pp. 1129-1152. https://doi.org/10.1080/00140130050084914

Kane, J. S. and Lawler, E. E. (1978), "Methods of peer assessment”, Psychological Bulletin, Vol. 85, pp. 555-586.

Kleinsmann, M. and Valkenburg, R. (2008), "Barriers and enablers for creating shared understanding in codesign projects", Design Studies, Vol. 29 No. 4, pp. 369-386. https://doi.org/10.1016/j.destud.2008.03.003

Keum, D. D. and See, K. E. (2017), "The influence of hierarchy on idea generation and selection in the innovation process", Organisation Science, Vol. 28 No. 4, pp. 653-669. https://doi.org/10.1287/orsc.2017.1142

Latham, G. P., and Wexley, K. N. (1981), "Increasing productivity through performance appraisal”,AddisonWesley Publishing Company

Layton, R.A. and Ohland, M.W. (2000). "Peer evaluations in teams of predominantly minority students". Proc. ASEE Annual Conference. St. Louis

Lindley, J., \& Wynn, L., 2018. Decision making in product design-bridging the gap between inception and reality. Design and Technology Education: an International Journal, 23(2), pp. 74-85.

May, G. L. and Gueldenzoph, L. E. (2006), "The impact of social style on peer evaluation ratings in project teams", Journal of Business Communication, Vol. 43, pp. 4-20. https://doi.org/10.1177/0021943605282368

Myers, D.G. (1982), "Polarizing effects of social interaction”, Group decision-making, ed. by H. Brandstatter, JH Davis, G. Stacker-Kreichgauer, pp. 125-161. London, Academic Press.

Oesch, N. and Dunbar, R.I.M. (2018), "Group size, communication, and familiarity effects in foraging human teams", Ethology, Vol. 124, pp. 483-495. https://doi.org/10.1111/ eth.12756

Ohland M.W., Loughry M.L., Woehr D.J., Bullard L.G., Felder R.M., Finelli C. J., Layton R. A., Pomeranz H.R. \& Schmucker D.G. (2012). The comprehensive assessment of team member effectiveness: development of a behaviorally anchored rating scale for self- and peer evaluation. Academy of Management Learning \& Education,11(4), 609-30.

Paswan,P.K and Gollakota,K. (2004), "Dimensions of peer evaluation, overall satisfaction, and overall evaluation: An investigation in a group task environment", Journal of Education for Business, Vol. 79 No. 4, pp. 225-231, 10.3200/JOEB.79.4.225-231

Perry-Smith, J.E. and Shalley, C.E.(2003), "The social side of creativity: a static and dynamic social network perspective", The Academy of Management Review, Vol. 28, No. 1, pp. 89-106. https://doi.org/10.5465/amr.2003.8925236

Ramachandran, K., Tereyagoglu, N. and Unal, M. (2017), "Help or Hindrance? The Role of Familiarity in Collaborative Product Development", Social Science Research Network (SSRN), pp. 17-27. http://dx.doi.org/10.2139/ssrn.3000522

Sherrard,W.R., Raafat,F. and Weaver,R.R.(1994), “An empirical study of peer bias in evaluations: students rating students", Journal of Education for Business, Vol. 70, pp. 43- 47. 10.1080/08832323.1994.10117723

Singh, V., Dong, A. and Gero, J. S. (2009), "Effects of social learning and team familiarity on team performance", SpringSim.

Singh, H., McComb, C. and Cascini, G. (2020a), "Modelling the dynamics of influence on individual thinking during idea generation in co-design teams", Ninth International Conference on Design Computing and Cognition (DCC20). Atlanta, USA

Singh, H., Cascini, G., and McComb, C. (2020b), "Analysing The Effect of Self-efficacy and Influencers on Design Team Performance", Proceedings of the Design Society: DESIGN Conference, Cambridge University Press. https://doi.org/10.1017/dsd.2020.64

Stokols, D., Misra, S., Moser, R. P., Hall, K. L. and Taylor, B. K. (2008), "The ecology of team science: understanding contextual influences on transdisciplinary collaboration", American journal of preventive medicine, Vol. 35 No. 2, pp. S96-S115. https://doi.org/10.1016/j.amepre.2008.05.003

Thompson, R. S. (2001), "Reliability, validity, and bias in peer evaluations of self-directed interdependent work teams", Proceedings of the 2001 American Society for Engineering Education Annual Conference \& Exposition, Vol. 6, pp. 1-37. American Society for Engineering Education

Watson, W. E., BarNir, A. and Pavur, R. (2010), "Elements influencing peer evaluation: An examination of individual characteristics, academic performance, and collaborative processes", Journal of Applied Social Psychology, Vol. 40, pp. 2995-3019. https://doi.org/10.1111/j.1559-1816.2010.00690.x

Wetmore III, W. R., Summers, J. D. and Greenstein, J. S. (2010), "Experimental study of influence of group familiarity and information sharing on design review effectiveness", Journal of Engineering Design, Vol. 21 No. 1, pp. 111-126. https://doi.org/10.1080/09544820802238217

Woodman, R. W., Sawyer, J. E. \& Griffin, R. W., 1993. Toward a Theory of Organizational Creativity. The Academy of Management Review, 18(2), pp. 293-321. 